\title{
(t)
}

\section{ANÁLISE COMPARATIVA ENTRE EXPANSÃO DOS CURSOS DE SERVIÇO SOCIAL EAD E PRESENCIAIS'}

\author{
COMPARATIVE ANALYSIS BETWEEN EXPANSION OF DISTANCE \\ EDUCATION AND IN-CLASSROOM SOCIAL SERVICE COURSES
}

\section{Larissa Dahmer Pereira² Andreza Telles dos Santos Ferreira ${ }^{3}$ Andréa Cristina Viana de Souza ${ }^{4}$}

\section{RESUMO}

O presente trabalho objetiva apreender o ritmo de crescimento dos cursos de Serviço Social ofertados na modalidade EaD, comparando-o com o dos cursos presenciais, buscando problematizar a participação de tais cursos (EaD) no processo formativo dos assistentes sociais brasileiros. Para a consecução do objetivo proposto, foram utilizados dados

1 Para a produção do presente artigo, a docente Larissa Dahmer Pereira contou com a participação das discentes de Mestrado, Andreza Telles dos Santos Ferreira, e Graduação, Andréa Cristina Viana de Souza, respectivamente, as quais colaboraram por meio da coleta dos dados em análise, sob a orientação/ supervisão da docente. Redação e análise do material são de responsabilidade da docente. $\mathrm{O}$ artigo é resultado de pesquisa em andamento no âmbito do Grupo de Estudos e Pesquisas em Educação Superior (GEPES), vinculado à Escola de Serviço Social da Universidade Federal Fluminense (ESS/UFF).

2 Assistente Social. Mestre e Doutora em Serviço Social pelo Programa de PósGraduação em Serviço Social da Universidade Federal do Rio de Janeiro (UFRJ). Docente da ESS/UFF, no curso de Graduação em Serviço Social e no Programa de Pós-Graduação em Serviço Social e Desenvolvimento Regional. Pesquisadora do GEPES. E-mail: larissadahmer@hotmail.com

3 Assistente Social formada pela ESS/UFF. Mestranda do Programa de PósGraduação em Serviço Social e Desenvolvimento Regional. Pesquisadora do GEPES. E-mail: andreza.telles@gmail.com

4 Discente de Graduação da Escola de Serviço Social/UFF. Bolsista PIBIC/CNPq (2012/2013) do Projeto de Pesquisa "Serviço Social na modalidade EaD: perfil e inserção no mercado de trabalho de alunos egressos do curso de Serviço Social" e pesquisadora do GEPES. E-mail: andreacvsouza@hotmail.com 


\section{temporalis}

estatísticos extraídos das Sinopses da Educação Superior, disponibilizadas pelo Instituto Nacional de Estudos e Pesquisas Educacionais Anísio Teixeira (INEP), referentes aos anos de 2006 a 2012. Os dados extraídos e analisados são os seguintes: (i) quantitativo de cursos; (ii) vagas ofertadas; (iii) matrículas; (iv) ingressantes; e (v) concluintes. A partir da extração dos dados, produziram-se gráficos com o objetivo de possibilitar a visualização do ritmo de crescimento de tais cursos, em comparação com os cursos presenciais. Além disso, problematizou-se o ritmo do crescimento dos cursos de Serviço Social na modalidade EaD, frente aos cursos presenciais, indicando possíveis tendências para a formação e o exercício profissional.

Palavras-chave: Ensino Superior. Formação Profissional em Serviço Social. Ensino Presencial. Ensino a Distância.

\section{ABSTRACT}

This paper aims to grasp the pace of growth of Social Service courses offered in distance education mode, comparing it with in-classroom courses, seeking to question the participation of such courses (DE) in Brazilian social workers formative process. To achieve the proposed objective, were used statistical data extracted from Higher Education Abstracts, provided by the National Institute for Studies and Educational Research Anísio Teixeira (INEP) for the years 2006 to 2011. Data extracted and analyzed are: (i) quantity of courses, (ii) vacancies offered, (iii) enrollment, (iv) entering and (v) graduates. From extracted data, charts were produced, with the purpose of enabling growth rate visualization of such courses compared to in-classroom courses. Moreover, we question the pace of growth of Social Service courses in distance education mode compared to in-classroom courses, indicating possible trends for the training and professional practice.

Keywords: Higher Education. Training in Social Service. In-classroom Education. Distance Education.

Submetido em 25/03/2014

Aceito em 16/07/2014

\section{INTRODUÇÃO}

O ensino superior brasileiro apresenta, desde os anos 1990, expressiva expansão, caracterizada pelo seguinte perfil: privado, de caráter mercantil e não universitário5. Tal expansão encontra-

5 O Censo do Ensino Superior, de 2011 (INEP/MEC, 2013), no que se refere à organização acadêmica das IES, mostra a predominância de faculdades, 
-se inserida em uma determinada lógica de ação estatal analisada por diversos autores como um processo de contrarreforma do Estado brasileiro. Ou seja, o Estado brasileiro vem, especialmente desde a década de 1990, desencadeando políticas de caráter econômico e social pautadas no ideário neoliberal, que propugna a ação do Estado limitada a de um agente regulador, liberando para o mercado espaços até então limitadamente explorados pelo capital, como as áreas de saúde, previdência e educação.

No que diz respeito ao ensino superior, a presença do setor privado não é uma novidade, visto sua constituição histórica ser marcada por tal participação. Contudo, o crescimento e a predominância do setor privado mercantil - cujo objetivo primordial é a lucratividade - a partir do regime ditatorial, principalmente nos anos 1990, apresentam um caráter inovador ${ }^{6}$.

A ação estatal na política educacional de nível superior a partir dos anos 1990 foi e é um determinante fundamental para proporcionar tal perfil expansionista: de um lado, enxugou recursos/ investimentos para o setor público7, precarizando as condições do trabalho docente ${ }^{8}$ e a formação profissional, proporcionando uma clara desvalorização da universidade pública brasileira; de outro, criou uma farta legislação, que garantiu subsídios fiscais e incentivos financeiros para o fortalecimento e a expansão do setor privado mercantil, atraindo segmentos das camadas médias para o consumo desse tipo de "serviço" educacional, descaracterizando-o como um direito social.

O ensino a distância (EaD), desde a Lei de Diretrizes e Bases da Educação Nacional (LDBEN), Lei 9.394, de 20 de dezembro de

especialmente no setor privado, as quais representam 89,8\% das instituições.

60 caráter inovador diz respeito essencialmente à presença majoritária de IES abertas com finalidade lucrativa, ou seja, empresas educacionais, o que foi impulsionado pelo regime militar. Até os anos 1960, a predominância no ensino superior era de instituições confessionais. Para a análise do processo de empresariamento do ensino superior brasileiro, cf. Germano (2005), Neves (2002) e Sguissardi (2008). Para uma análise dos governos FHC e parte do governo Lula, cf. Lima (2007).

7 Sobre o financiamento do ensino superior, consultar estudos de Amaral (2003 e 2009).

8 Sobre a intensificação do trabalho docente, conferir trabalho de Sguissardi e Silva Junior (2009). 
1996, regulamentado a partir do art. $80^{9}$ da referida lei (BRASIL, 1996), passou a ser largamente utilizado no país, inicialmente voltado para as Licenciaturas (Formação de Professores) e, posteriormente, abarcou também os Bacharelados, incluindo o curso de Serviço Social ${ }^{10}$. Trata-se de uma modalidade de ensino que possibilita ao setor privado mercantil uma rápida e lucrativa expansão de matrículas ${ }^{11}$, constituindo-se como uma importante alternativa a um mercado cujo público consumidor apresenta historicamente limitações financeiras.

O curso de graduação em Serviço Social - criado nos anos 1930 no país e cujo crescimento relaciona-se com o processo de urbanização e industrialização, associado à necessidade de enfrentamento estatal/burguês frente às expressões da "questão social" e às insatisfações de diversos segmentos da classe trabalhadora - assistiu, a partir dos anos 2000, ao surgimento dos primeiros cursos de EaD.

9 “Art. $80^{\circ}$. O Poder Público incentivará o desenvolvimento e a veiculação de programas de ensino a distância, em todos os níveis e modalidades de ensino, e de educação continuada. $\S 1^{\circ}$. A educação a distância, organizada com abertura e regime especiais, será oferecida por instituições especificamente credenciadas pela União. $\S 2^{\circ}$. A União regulamentará os requisitos para a realização de exames e registro de diploma relativos a cursos de educação a distância. $\S^{\circ} 3^{\circ}$. As normas para produção, controle e avaliação de programas de educação a distância e a autorizaçã̃o para sua implementação, caberão aos respectivos sistemas de ensino, podendo haver cooperação e integração entre os diferentes sistemas. $\S 4^{\circ}$. A educação a distância gozará de tratamento diferenciado, que incluirá: I - custos de transmissão reduzidos em canais comerciais de radiodifusão sonora e de sons e imagens; II - concessão de canais com finalidades exclusivamente educativas; III - reserva de tempo mínimo, sem ônus para o Poder Público, pelos concessionários de canais comerciais" (BRASIL, 1996, s/p).

10 Cf. INEP/MEC (2013).

11 Embora esse não seja o foco do presente artigo, cabe destacar a fusão de grandes empresas educacionais, recentemente (abril de 2013), como Kroton e Anhanguera, que criou o maior grupo educacional do mundo, com valor de mercado de cerca de R\$ 12 bilhões e 1 milhão de alunos: "O forte da Anhanguera é a aprendizagem em sala de aula, enquanto a Kroton ganhou musculatura com a criação de sistemas de ensino, uma marca do DNA do Colégio Pitágoras, de Belo Horizonte, fundado em 1966, e com a educação a distância. Um nicho no qual se tornou relevante somente após a compra da paranaense Unopar, em 2012, pela qual pagou $\mathrm{R} \$ 1,2$ bilhão. A vantagem dessa modalidade é seu baixo custo, o que garante uma margem de ganhos de cerca de 30\%. Índice maior até mesmo que o da Kroton (27,6\%), a mais bem administrada do setor". Disponível em: <http://www.istoedinheiro.com.br/noticias/117790_FUSAO+KROTON+E+AN HANGUERA+LICAO+DE+NEGOCIOS>. Acesso em: 03 sēt. 2013. 
Desde o surgimento dos primeiros cursos de Serviço Social na referida modalidade, a categoria profissional, por meio de suas entidades representativas, vem se manifestando publicamente contrária à inserção de EaD na graduação em Serviço Social, argumentando a sua radical incompatibilidade com uma formação que garanta um perfil de assistente social crítico e qualificado nas três dimensões do exercício profissional: teórico-metodológica, ético-política e técnico-operativa ${ }^{12}$.

Isto é, há quase uma década argumenta-se para o risco de reconfiguração do perfil profissional, formado na modalidade EaD, sem a devida vivência/interlocução acadêmica, destituído do contato com movimentos sociais históricos (como o docente e o estudantil), com bibliografia enxuta, ausência do indissociável tripé ensino, pesquisa e extensão, além de sérias irregularidades relacionadas à supervisão direta de estágio em Serviço Social. Tal perfil de formação associa-se à necessidade de reconfiguração do perfil profissional, que deve coadunar com o perfil de política social minimalista, focal e residual, cuja manutenção depende da forte ação estatal brasileira, pautada pelo ideário neoliberal.

Além da primordial resistência política a um perfil de formação que precariza e fragiliza o exercício profissional em seu aspecto crítico e questionador da sociabilidade burguesa, da política social vigente e da histórica desigualdade presente na formação social brasileira - inerente à lógica de acumulação capitalista, especialmente em um país capitalista periférico como o Brasil -, fazem-se necessários o desenvolvimento e o fortalecimento de pesquisas que possibilitem acompanhar e desvelar os rumos da formação profissional dos assistentes sociais brasileiros, que impactam fortemente o exercício profissional.

12 Destaca-se que a crítica das entidades representativas da categoria profissional não se restringe a um viés ideológico, mas é uma posição política, preocupada com o perfil de assistente social formado em tal modalidade, visto a precariedade do processo formativo em todas as dimensões: teórico-metodológica, técnicooperativa e ético-política. A supervisão de estágio vem sendo alvo de inúmeras denúncias aos Conselhos, demonstrando a precariedade da formação e os limites dessa modalidade de ensino para a formação de graduandos em Serviço Social. Cf. documento das entidades: CFESS/ABEPSS/ENESSO (2010). 


\section{temporalis}

Nessa direção, o presente trabalho objetiva apreender o ritmo de crescimento dos cursos de Serviço Social ofertados na modalidade EaD, comparando-o com o dos cursos presenciais, buscando problematizar a participação de tais cursos (EaD) no processo formativo dos assistentes sociais brasileiros.

\section{METODOLOGIA}

Para a consecução do objetivo proposto - apreender o ritmo de crescimento dos cursos de Serviço Social ofertados na modalidade EaD, comparando-o com o dos cursos presenciais -, foram utilizados dados estatísticos extraídos das Sinopses da Educação Superior, disponibilizadas pelo Instituto Nacional de Estudos e Pesquisas Educacionais Anísio Teixeira (INEP), autarquia federal vinculada ao Ministério da Educação (MEC) ${ }^{13}$.

Utilizamos as Sinopses Estatísticas referentes aos anos de 2006 a 2012. O recorte temporal do ano de 2006 justifica-se em virtude de o surgimento do primeiro curso de Serviço Social na modalidade EaD ter ocorrido no respectivo ano. Assim, a comparação relativa aos cursos presenciais de Serviço Social será realizada a partir do ano de 2006.

Os dados extraídos e analisados são os seguintes: (i) quantitativo de cursos; (ii) vagas ofertadas; (iii) matrículas; (iv) ingressos; e (v) concluintes.

A partir da extração dos dados, produzimos gráficos com o objetivo de possibilitar a visualização do ritmo de crescimento de tais cursos, em comparação com os cursos presenciais. A seguir, problematizamos o ritmo do crescimento dos cursos de Serviço Social na modalidade EaD, frente aos cursos presenciais, indicando possíveis tendências para a formação e o exercício profissional.

13 "O Instituto Nacional de Estudos e Pesquisas Educacionais Anísio Teixeira (INEP) é uma autarquia federal vinculada ao Ministério da Educação (MEC), cuja missão é promover estudos, pesquisas e avaliações sobre o Sistema Educacional Brasileiro com o objetivo de subsidiar a formulação e implementação de políticas públicas para a área educacional a partir de parâmetros de qualidade e equidade, bem como produzir informações claras e confiáveis aos gestores, pesquisadores, educadores e público em geral". Disponível em: <http://portal. inep.gov.br/conheca-o-inep >. Acesso em: 21 ago. 2013. 


\section{RESULTADOS}

O primeiro curso de Serviço Social desenvolvido na modalidade EaD iniciou seu funcionamento no ano de 2006, conforme é possível visualizar na tabela a seguir. Cabe destacar o interesse das Instituições de Ensino Superior (IES) privadas mercantis, com fins lucrativos, na abertura de tais cursos, sendo exatamente estas as que mais ofertam vagas. A Universidade Anhanguera (UNIDERP) e a do Norte do Paraná (UNOPAR) ofertam juntas 37.950 vagas para o curso de Serviço Social, mais de $50 \%$ das vagas totais ofertadas anualmente (Tabela 1). Tais dados nos indicam que o curso de Serviço Social na modalidade EaD, provavelmente, é atraente para as empresas educacionais quanto à lucratividade. 
Tabela 1 - Cursos de Serviço Social EaD: IES, natureza jurídica, vagas totais anuais e data de funcionamento do curso

\begin{tabular}{|c|c|c|c|}
\hline IES & $\begin{array}{c}\text { Categoria } \\
\text { administrativa }\end{array}$ & $\begin{array}{l}\text { Vagas } \\
\text { totais } \\
\text { anuais }\end{array}$ & \begin{tabular}{|c|} 
Data de \\
funcionamento \\
do curso
\end{tabular} \\
\hline $\begin{array}{c}\text { UNIVERSIDADE DO } \\
\text { TOCANTINS - UNITINS }{ }^{14}\end{array}$ & Pública estadual & 2760 & $02 / 02 / 2006$ \\
\hline $\begin{array}{l}\text { UNIVERSIDADE NOVE DE } \\
\text { JULHO - UNINOVE }\end{array}$ & $\begin{array}{l}\text { Privada sem fins } \\
\text { lucrativos }\end{array}$ & 2500 & $10 / 02 / 2006$ \\
\hline $\begin{array}{c}\text { UNIVERSIDADE TIRADENTES } \\
- \text { UNIT }\end{array}$ & $\begin{array}{c}\text { Privada com fins } \\
\text { lucrativos }\end{array}$ & 1100 & $10 / 06 / 2006$ \\
\hline $\begin{array}{l}\text { UNIVERSIDADE DE UBERABA } \\
\text { - UNIUBE }\end{array}$ & $\begin{array}{l}\text { Privada sem fins } \\
\text { lucrativos }\end{array}$ & 55 & $01 / 02 / 2007$ \\
\hline $\begin{array}{c}\text { UNIVERSIDADE } \\
\text { ANHANGUERA - UNIDERP }\end{array}$ & $\begin{array}{c}\text { Privada com fins } \\
\text { lucrativos }\end{array}$ & 16800 & $07 / 02 / 2007$ \\
\hline $\begin{array}{l}\text { UNIVERSIDADE DO NORTE } \\
\text { DO PARANÁ - UNOPAR }\end{array}$ & $\begin{array}{c}\text { Privada com fins } \\
\text { lucrativos }\end{array}$ & 21150 & $12 / 02 / 2007$ \\
\hline $\begin{array}{l}\text { UNIVERSIDADE DO VALE DO } \\
\text { ITAJAÍ (UNIVALI) }\end{array}$ & $\begin{array}{c}\text { Privada sem fins } \\
\text { lucrativos }\end{array}$ & 3000 & $23 / 02 / 2007$ \\
\hline $\begin{array}{c}\text { CENTRO UNIVSERSITÁRIO } \\
\text { NEWTON PAIVA }\end{array}$ & $\begin{array}{l}\text { Privada com fins } \\
\text { lucrativos }\end{array}$ & 2500 & $01 / 02 / 2008$ \\
\hline $\begin{array}{c}\text { UNIVERSIDADE PAULISTA - } \\
\text { UNIP }\end{array}$ & $\begin{array}{c}\text { Privada sem fins } \\
\text { lucrativos }\end{array}$ & 60 & $18 / 02 / 2008$ \\
\hline $\begin{array}{c}\text { UNIVERSIDADE LUTERANA } \\
\text { DO BRASIL - ULBRA }\end{array}$ & $\begin{array}{l}\text { Privada sem fins } \\
\text { lucrativos }\end{array}$ & 4000 & $31 / 03 / 2008$ \\
\hline $\begin{array}{c}\text { UNIVERSIDADE DE SANTO } \\
\text { AMARO - UNISA }\end{array}$ & $\begin{array}{l}\text { Privada sem fins } \\
\text { lucrativos }\end{array}$ & 2300 & $22 / 04 / 2008$ \\
\hline
\end{tabular}

14 A UNITINS foi descredenciada para a oferta de cursos de graduação na modalidade EaD pelo Ministério da Educação, através da Portaria n. 44, de 18 de agosto de 2009, em virtude de uma série de irregularidades. Em 24 de junho de 2010, 25/06/2010, a Portaria n. 837 - após recurso da IES - recredenciou a UNITINS para compor o sistema Universidade Aberta do Brasil (UAB), tendo de se adequar ao Termo de Cooperação Técnica. Os discentes que estavam cursando Serviço Social na modalidade EaD obtiveram o direito a ter seus diplomas reconhecidos. A UNITINS reabriu vestibular para o curso de Serviço Social, em 2010/02, na modalidade presencial e passou a oferecer também cursos de Letras e Pedagogia na modalidade EaD, através do sistema UAB, conforme matéria veiculada pela IES em 01/06/2010. Cf. UNITINS: <http://www.unitins.br/ portal/Noticia_principal_Visualizar.aspx?in=2030>.

15 Na base do Sistema e-MEC, o curso de Serviço Social da UNIVALI na modalidade EaD encontra-se em extinção. Não foi identificada nenhuma informação na página da IES sobre o curso de Serviço Social na modalidade EaD e presencial. 


\begin{tabular}{|c|c|c|c|}
\hline IES & $\begin{array}{c}\text { Categoria } \\
\text { administrativa }\end{array}$ & $\begin{array}{l}\text { Vagas } \\
\text { totais } \\
\text { anuais }\end{array}$ & $\begin{array}{c}\text { Data de } \\
\text { funcionamento } \\
\text { do curso } \\
\end{array}$ \\
\hline $\begin{array}{c}\text { CENTRO UNIVERSITÁRIO } \\
\text { LEONARDO DA VINCI - } \\
\text { UNIASSELVI }\end{array}$ & $\begin{array}{l}\text { Privada com fins } \\
\text { lucrativos }\end{array}$ & 1300 & $02 / 05 / 2008$ \\
\hline $\begin{array}{c}\text { CENTRO UNIVERSITÁRIO } \\
\text { DA GRANDE DOURADOS - } \\
\text { UNIGRAN }\end{array}$ & $\begin{array}{l}\text { Privada sem fins } \\
\text { lucrativos }\end{array}$ & 3000 & $01 / 08 / 2008$ \\
\hline $\begin{array}{l}\text { CENTRO UNIVERSITÁRIO } \\
\text { CLARETIANO - CEUCLAR }\end{array}$ & $\begin{array}{c}\text { Privada sem fins } \\
\text { lucrativos }\end{array}$ & 900 & $04 / 02 / 2009$ \\
\hline $\begin{array}{c}\text { UNIVERSIDADE DE } \\
\text { SALVADOR - UNIFACS }\end{array}$ & $\begin{array}{c}\text { Privada com fins } \\
\text { lucrativos }\end{array}$ & 1101 & $03 / 02 / 2010$ \\
\hline $\begin{array}{c}\text { UNIVERSIDADE ESTÁCIO DE } \\
\text { SÁ - UNESA }\end{array}$ & $\begin{array}{c}\text { Privada com fins } \\
\text { lucrativos }\end{array}$ & 1740 & $22 / 07 / 2010$ \\
\hline $\begin{array}{l}\text { UNIVERSIDADE SALGADO DE } \\
\text { OLIVEIRA - UNIVERSO }\end{array}$ & $\begin{array}{l}\text { Privada sem fins } \\
\text { lucrativos }\end{array}$ & 2000 & $12 / 09 / 2010$ \\
\hline $\begin{array}{c}\text { UNIVERSIDADE BRAZ CUBAS } \\
- \text { UBC }\end{array}$ & $\begin{array}{l}\text { Privada com fins } \\
\text { lucrativos }\end{array}$ & 400 & $02 / 02 / 2011$ \\
\hline $\begin{array}{c}\text { UNIVERSIDADE } \\
\text { METROPOLITANA DE SANTOS } \\
\text { - UNIMES }\end{array}$ & $\begin{array}{l}\text { Privada sem fins } \\
\text { lucrativos }\end{array}$ & 0 & $15 / 02 / 2011$ \\
\hline $\begin{array}{c}\text { CENTRO UNIVERSITÁRIO } \\
\text { UNISEB }\end{array}$ & $\begin{array}{c}\text { Privada com fins } \\
\text { lucrativos }\end{array}$ & 5000 & $20 / 07 / 2011$ \\
\hline $\begin{array}{c}\text { UNIVERSIDADE POTIGUAR - } \\
\text { UNP }\end{array}$ & $\begin{array}{l}\text { Privada com fins } \\
\text { lucrativos }\end{array}$ & 249 & $13 / 02 / 2012$ \\
\hline UNICID & $\begin{array}{c}\text { Privada com fins } \\
\text { lucrativos }\end{array}$ & 0 & $01 / 01 / 2014$ \\
\hline $\begin{array}{c}\text { CENTRO UNIVERSITÁRIO DE } \\
\text { MARINGÁ - UNICESUMAR }\end{array}$ & $\begin{array}{c}\text { Privada com fins } \\
\text { lucrativos }\end{array}$ & 2000 & $03 / 02 / 2014$ \\
\hline $\begin{array}{c}\text { UNIVERSIDADE DE FRANCA - } \\
\text { UNIFRAN }\end{array}$ & $\begin{array}{c}\text { Privada com fins } \\
\text { lucrativos }\end{array}$ & 300 & $03 / 02 / 2014$ \\
\hline $\begin{array}{l}\text { UNIVERSIDADE CRUZEIRO DO } \\
\text { SUL - UNICSUL }\end{array}$ & $\begin{array}{l}\text { Privada com fins } \\
\text { lucrativos }\end{array}$ & 300 & $03 / 02 / 2014$ \\
\hline $\begin{array}{l}\text { CENTRO UNIVERSITÁRIO } \\
\text { JORGE AMADO - UNIJORGE }\end{array}$ & $\begin{array}{c}\text { Privada com fins } \\
\text { lucrativos }\end{array}$ & 500 & $X^{*}$ \\
\hline $\begin{array}{c}\text { CENTRO UNIVERSITÁRIO DO } \\
\text { NORTE - UNINORTE }\end{array}$ & $\begin{array}{l}\text { Privada com fins } \\
\text { lucrativos }\end{array}$ & 0 & $X^{*}$ \\
\hline Total de vagas anuais & $\mathrm{X}$ & 75015 & $x$ \\
\hline
\end{tabular}

Fonte: Elaborada pelas autoras com base em dados retirados do Sistema e-MEC ${ }^{16}$.

*A base de dados e-MEC não apresenta informações sobre esses dados.

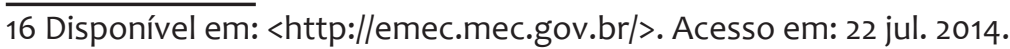




\section{tempordils}

Ao observar o ritmo de abertura de novos cursos de Serviço Social na modalidade EaD, constatamos sua predominância, especialmente se compararmos com os cursos ofertados na modalidade presencial e, ainda, considerando que cada IES oferta geralmente vagas em caráter massivo, muito superior aos cursos presenciais, o que se relaciona com a própria natureza de tal modalidade de ensino.

O Gráfico 1 confirma a discussão realizada de forma introdutória neste trabalho: o ritmo de crescimento da abertura de novos cursos de Serviço Social na modalidade EaD é vertiginoso, enquanto os cursos presenciais apresentaram, entre 2006 e 2012, um percentual de aumento de $67,85 \%$, os ofertados na modalidade EaD saltaram de um curso para dezoito, com crescimento de $1.700 \%{ }^{17}$.

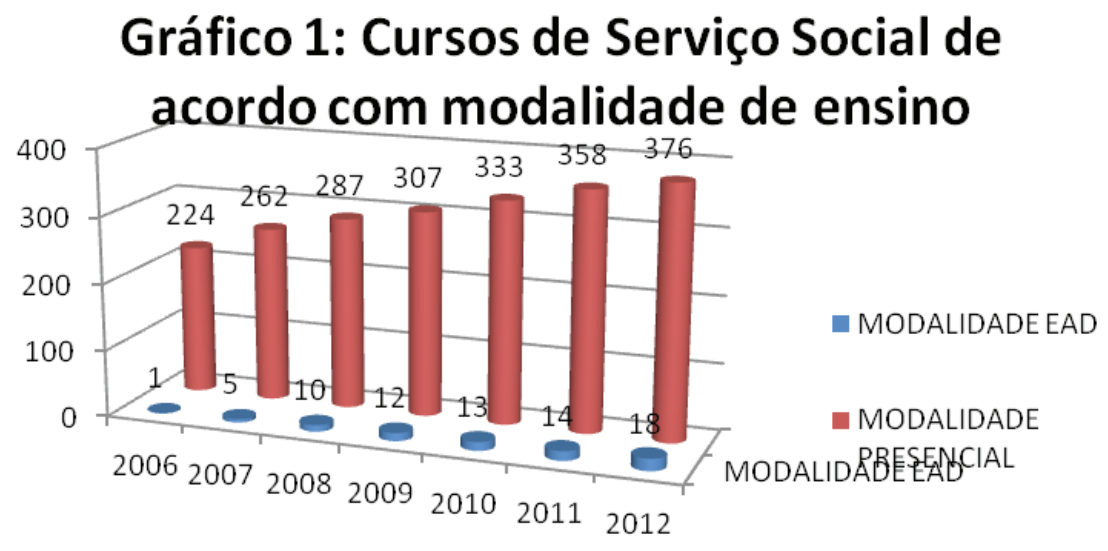

Fonte: Sinopses Estatísticas (INEP/MEC, 2006, 2007, 2008, 2009, 2010, 2011, 2012).

\footnotetext{
*Nas sinopses estatísticas dos anos de 2006, 2007 e 2008 não havia uma soma do total do quantitativo de cursos de Serviço Social na modalidade EaD. Portanto, foi realizada a soma dos dados para obter o total.
}

17 Conforme Tabela 1, constam registrados no sistema e-MEC 26 (vinte e seis) cursos de Serviço Social na modalidade EaD, enquanto o Gráfico 1 apresenta em 2012 o total de 18 (dezoito) cursos. Essa diferença é justificada pelo fato de trabalharmos, na construção dos gráficos, com os dados consolidados extraídos das Sinopses Estatísticas da Educação Superior, até o ano de 2012. A partir de 2012, surgiram mais 6 (seis) cursos. Na Sinopse, os dados dos cursos em extinção - UNIVALI - e descredenciados - UNITINS - provavelmente não foram considerados, chegando-se, assim, a 18 (dezoito) cursos no ano de 2012. 
Embora o percentual de crescimento de cursos na modalidade $\operatorname{EaD}(1.700 \%)$ tenha sido impressionante, a oferta de vagas seguiu um ritmo um pouco menor: podemos verificar que, de 2007 a 2008, a oferta mais do que triplicou. Reduz-se desde 2009, com significativa queda em 2011. Em 2012, há novo aumento nas vagas ofertadas na modalidade EaD. Já as vagas ofertadas em cursos presenciais seguiram um ritmo de crescimento ascendente, conforme quadro a seguir.

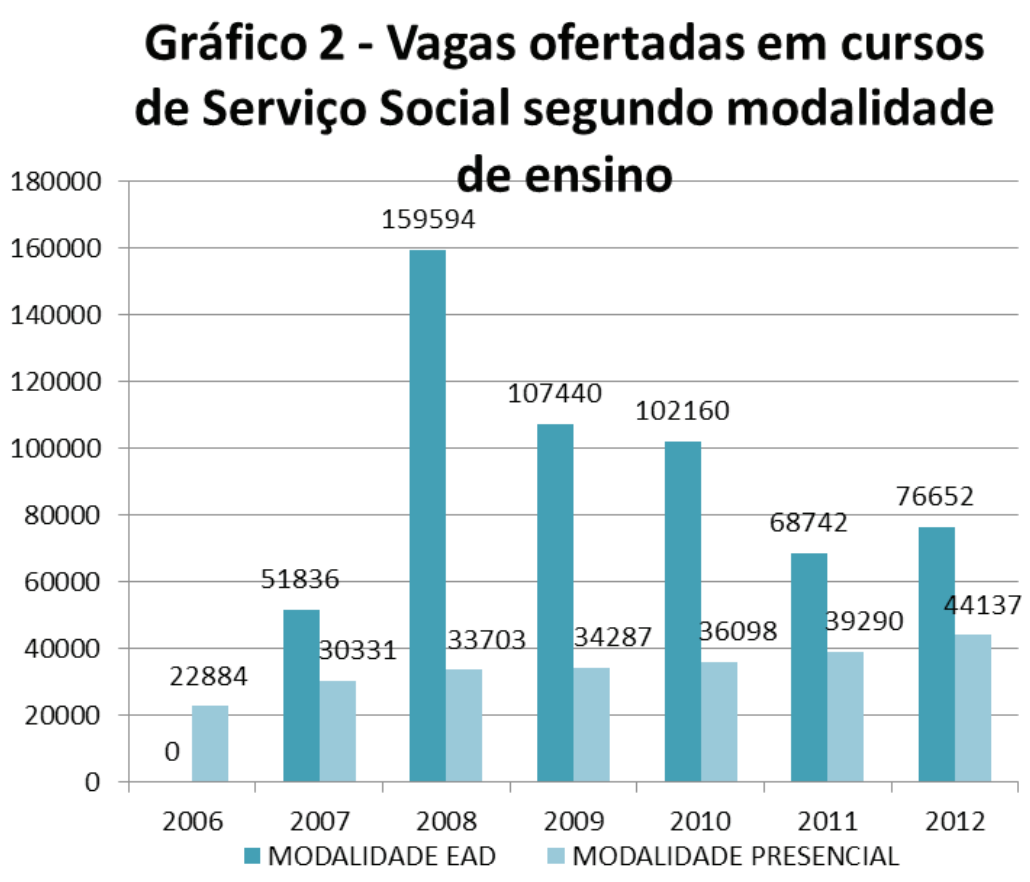

Fonte: Sinopses Estatísticas (INEP/MEC, 2006, 2007, 2008, 2009, 2010, 2011, 2012).

*Nas sinopses estatísticas dos anos de 2006, 2007 e 2008, não havia uma soma do total das vagas ofertadas em cursos de Serviço Social na modalidade EaD. Portanto, foi realizada a soma dos dados para obter o total.

Ao se analisar o crescimento das matrículas a cada ano (Gráfico 3), apreende-se que o ano de 2008 apresentou um expressivo crescimento na modalidade EaD, quadruplicando as matrículas, o que se relaciona com o número de cursos abertos naquele ano: em 2008, 06 (seis) IES passaram a ofertar o curso 


\section{temporalis}

de Serviço Social nessa modalidade (cf. Tabela 1), sendo este ano, desde 2006 até 2012, o que mais apresentou abertura de novos cursos de EaD. O quantitativo de matrículas caiu substancialmente de 2008 para 2009, com leve aumento em 2010 e 2011. No ano de 2012, o quantitativo de matrículas nos cursos EaD (97.428 matrículas) quase se equipara ao ano de 2008 (101.890 matrículas), quando houve o "pico" no quantitativo de matrículas nesses cursos.

Observa-se a relação entre redução da oferta de vagas (Gráfico 2) e redução das matrículas (Gráfico 3) nos cursos de Serviço Social realizados na modalidade EaD. O descredenciamento da UNITINS, no ano de 2009, indica ser um dos principais motivos para a redução no que concerne tanto às matrículas quanto às vagas nessa modalidade ${ }^{18}$.

Comparando-se o quantitativo de matrículas de acordo com a modalidade de ensino (Gráfico 3), apreende-se que os cursos presenciais apresentaram crescimento num movimento contínuo, enquanto nos cursos EaD o movimento foi descontínuo, com um salto em 2008 e relativa redução a partir de 2009, com recuperação em 2012. Apesar de tal descontinuidade, os cursos disponíveis na modalidade EaD vêm superando o quantitativo de matrículas ofertadas pelos cursos presenciais desde 2008, 0 que indica a atratividade do curso de Serviço Social em tal modalidade de ensino para um público consumidor desse formato de graduação.

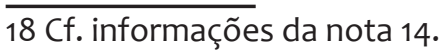




\section{Gráfico 3 - Matrículas em cursos de Serviço Social segundo modalidade de ensino}

MODALIDADE EAD MODALIDADE PRESENCIAL

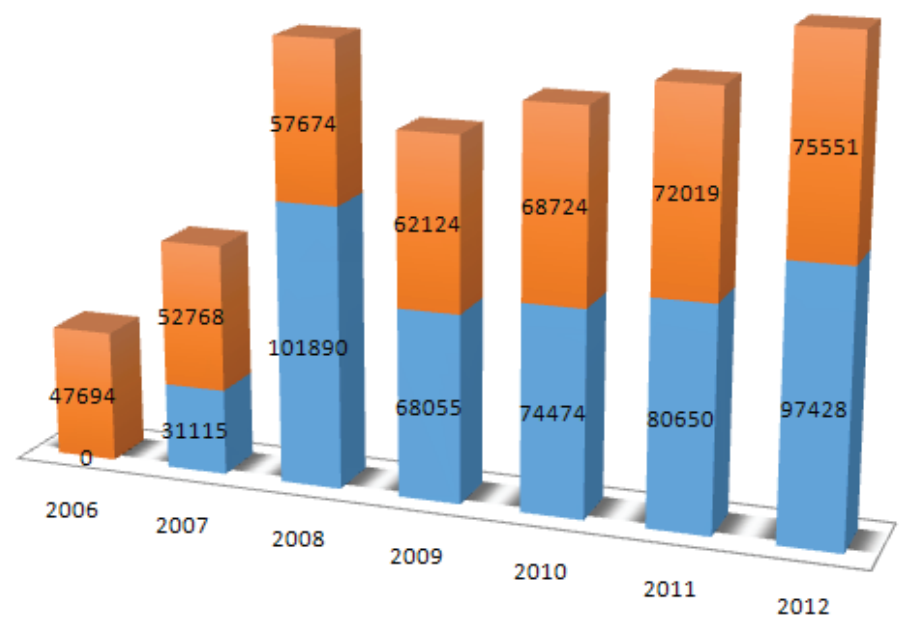

Fonte: Sinopses Estatísticas (INEP/MEC, 2006, 2007, 2008, 2009, 2010, 2011, 2012).

*Nas sinopses estatísticas dos anos de 2006, 2007 e 2008 não havia uma soma do total das matrículas em cursos de Serviço Social na modalidade

EaD. Portanto, foi realizada a soma dos dados para obter o total.

O Gráfico 4 nos informa mais uma vez a descontinuidade do quantitativo de ingressantes a cada ano na modalidade EaD, considerando o ano de 2008, com um salto de ingressantes (77.286) e, já no ano de 2009, uma expressiva queda, com 22.811 ingressantes, estabilizando-se o ingresso de novos alunos nos anos seguintes, 2010 a 2012. A modalidade EaD novamente supera os cursos ofertados na modalidade presencial, no que diz respeito ao quantitativo de ingressantes, conforme o gráfico expressa a seguir: 


\section{temporalis}

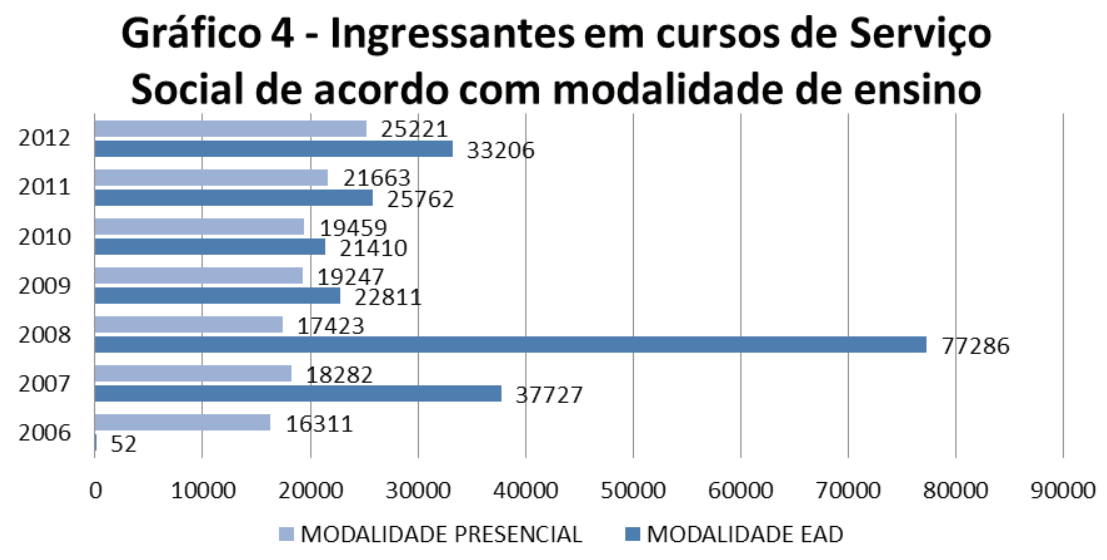

Fonte: Sinopses Estatísticas (INEP/MEC, 2006, 2007, 2008, 2009, 2010, 2011).

*Nas sinopses estatísticas dos anos de 2006, 2007 e 2008 não havia uma soma do total dos ingressantes em cursos de Serviço Social na modalidade

EaD. Portanto, foi realizada a soma dos dados para obter o total.

*O total de ingressantes de EaD é resultado da soma da quantidade de ingressos por vestibular e quantidade de ingressos por outros processos seletivos.

*O número de ingressantes foi obtido através da tabela das sinopses estatísticas, que abrange todas as formas de ingressos

(por vestibular e por outros processos seletivos).

Por fim, faz-se necessário analisar o quantitativo de concluintes a cada ano, por modalidade de ensino: a modalidade EaD passou a formar mais profissionais do que a presencial. O Gráfico 5 ilustra tal assertiva: a modalidade presencial formou, em 2011, mais do que o dobro de profissionais, em ritmo ascendente desde o ano de 2006, sendo o crescimento, entre 2006 e 2012, da ordem de $59,10 \%$. Já os cursos de Serviço Social ofertados na modalidade EaD apresentaram um movimento descontínuo, com expressivo quantitativo de concluintes em 2010 e brusca queda em 2011, reduzindo-se o número de concluintes praticamente pela metade. Em 2012, contudo, houve um salto expressivo de concluintes: 15.307. Ou seja, de 2009 a 2012, a modalidade EaD apresentou um aumento de $372 \%$ com relação ao número de concluintes no curso de Serviço Social, enquanto o aumento nos cursos presenciais foi de $18,2 \%$, no mesmo período, demonstrando o peso dos cursos 
de Serviço Social na modalidade EaD para a formação de novos assistentes sociais.

\section{Gráfico 5 - Concluintes em cursos de Serviço Social segundo modalidade de ensino}

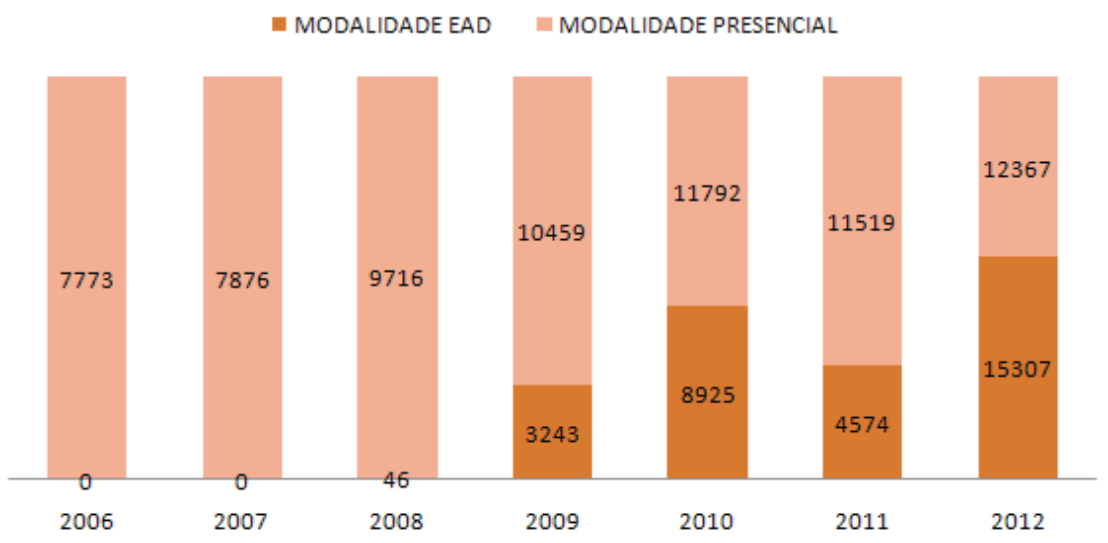

Fonte: Sinopses Estatísticas (INEP/MEC, 2006, 2007, 2008, 2009, 2010, 2011, 2012).

*Nas sinopses estatísticas dos anos de 2006, 2007 e 2008 não havia uma soma do total dos concluintes em cursos de Serviço Social na modalidade

EaD. Portanto, foi realizada a soma dos dados para obter o total.

\section{CONCLUSÃO}

Após a exposição dos dados relativos aos cursos de Serviço Social ofertados na modalidade EaD e presencial, é possível levantar algumas tendências e problematizar questões referentes aos rumos da formação de assistentes sociais no país.

Conforme ilustrado pela Tabela 1 e pelo Gráfico 1, o interesse das IES com fins lucrativos por tal curso é explícito: a abertura de cursos de Serviço Social na modalidade EaD ocorreu de forma vertiginosa entre os anos de 2006 e 2012, com um salto em 2008 , ano em que mais foram abertos cursos de Serviço Social na referida modalidade.

Contudo, ao analisarmos o ritmo de crescimento de vagas, matrículas, ingressantes e concluintes, apreendemos que este foi menor em relação à abertura de cursos na modalidade EaD. 


\section{temporalis}

No que concerne às vagas ofertadas nessa modalidade, houve um salto, também no ano de 2008, com expressiva redução da oferta nos anos seguintes. O mesmo aconteceu com as matrículas, que tiveram um movimento descendente - de 2008 para 2009 - e tornaram a apresentar crescimento de 2010 a 2012, superando as matrículas dos cursos presenciais.

O movimento em relação aos ingressantes foi parecido: drástica redução de 2008 para 2009, ainda redução de 2009 para 2010 e elevação relativa nos anos seguintes (2011 e 2012). Exceto em 2006 - ano de abertura dos cursos na modalidade EaD - em todos os demais anos (de 2007 a 2012), os ingressantes na referida modalidade apresentaram-se sempre em quantitativo superior ao dos ingressantes na modalidade presencial, o que se relaciona com a natureza da modalidade EaD, caracterizada pela oferta massiva de vagas, matrículas e ingressos.

Um dado que "salta aos olhos" é o quantitativo de concluintes na modalidade EaD no ano de 2012: 15.307, frente aos 12.367 formados em cursos presenciais. Até 2011, os concluintes formados na modalidade presencial eram sempre maioria, sendo tal realidade ultrapassada no ano seguinte.

A partir da exposição e análise dos dados, é possível apresentar algumas tendências que, a nosso ver, merecem ser acompanhadas nos próximos anos, tanto pelos grupos de pesquisa na área de política educacional, formação e exercício profissional quanto pelas entidades da categoria, preocupadas com os rumos da formação profissional, como a Associação Brasileira de Ensino e Pesquisa em Serviço Social (ABEPSS), o Conselho Federal de Serviço Social (CFESS) e a ENESSO (Executiva Nacional dos Estudantes de Serviço Social):

(i) apreende-se o claro interesse mercantil das IES que ofertam vagas nos cursos de Serviço Social na modalidade EaD, por meio da massiva oferta de vagas. Tal interesse relaciona-se com o fato de o curso de Serviço Social ser relativamente "barato", tanto para quem o explora (as IES) comercialmente quanto para quem o consome (os estudantes), com matrículas relativamente baratas, considerando-se as mensalidades dos cursos 
privados presenciais ${ }^{19}$, além dos custos extras que o estudante tem em um curso presencial, como deslocamento diário (transporte), alimentação e compra de textos para leitura. Portanto, a tendência é que as IES continuem a explorar esse nicho de mercado educacional, investindo junto ao público consumidor em propaganda fortalecedora da imagem do EaD como facilitador do acesso ao diploma em diversas dimensões, como a econômica (na medida em que é mais acessível do que cursos presenciais privados ), a relação do tempo gasto em transporte e idas à IES (o que é praticamente suprimido na modalidade EaD, excetuando-se as idas aos polos), a flexibilidade para o estudo no que diz respeito à sua gestão, dentre outros fatores.

(ii) embora até 2011 os cursos ofertados na modalidade EaD não tenham apresentado o mesmo quantitativo de concluintes que o dos cursos presenciais, a partir de 2012, o peso da formação de assistentes sociais via cursos EaD vem à tona, com um quantitativo significativo frente aos cursos presenciais.

Após o levantamento e a análise dos dados, especialmente levando-se em consideração a quantidade de concluintes formados via EaD, indica-se a necessidade do desenvolvimento permanente de pesquisas que acompanhem os impactos do EaD na formação e no exercício profissional, bem como busquem conhecer como vem se dando a convivência - no que diz respeito ao

19 "A publicação dos balanços trimestrais de grandes instituições de ensino como Kroton, Anhanguera e Estácio, que possuem tanto cursos presenciais quanto a distância em vários níveis de ensino, mostram a diferença de preços pagos por alunos de cursos nas duas metodologias, de modo a permitir a comparação da diferença numa mesma instituição. Os balanços dessas três empresas, publicados em agosto, mostram que a diferença de preços nas mensalidades (ticket médio) é grande. Na Estácio, por exemplo, o ticket médio de um curso a distância chega a quase um terço (35\%) do valor de cursos presenciais. A Kroton mantém seus cursos a distância com uma relação percentual semelhante (35,5\% do preço dos cursos presenciais). A Anhanguera também mantém preços bem menores para o EaD (50,14\% do preço dos cursos presenciais). Apesar desses preços menores, todas as instituições de ensino registraram lucros brutos e líquidos com os cursos a distância. Na Kroton, por exemplo, o lucro bruto com EaD no primeiro semestre de 2013 foi de R\$ 230 milhões, enquanto o lucro bruto com cursos presenciais foi de $\mathrm{R} \$ 283,7$ milhôes. No primeiro semestre de 2013, os cursos a distância representaram 34\% da receita líquida e $48 \%$ do resultado operacional do negócio Ensino Superior para a Kroton, o que demonstra a importância dessa modalidade para a companhia". Disponível em: <http://www. acheseucurso.com.br/preco-dos-cursos-a-distancia-sao-quase-um-terco-dospresenciais.aspx>. Acesso em: 03 set. 2013. 


\section{temporalis}

direcionamento social dado ao exercício - entre os profissionais formados em modalidades radicalmente distintas e a convivência entre discentes e supervisores de campo.

Ainda, sem subdimensionar o EaD na formação de profissionais de Serviço Social, considera-se fundamental acompanhar também o ensino presencial ainda como importante formador de assistentes sociais, sendo estratégico para a formação e o exercício profissionais, inclusive na convivência com estudantes e colegas formados na modalidade EaD.

Destaca-se que o perfil formativo de assistentes sociais na modalidade presencial caracteriza-se ainda pela inserção dos cursos em IES privadas mercantis, o que aponta limites graves para o processo formativo, como a não realização de pesquisa/ensino/ extensão e a precarização e intensificação do trabalho docente, impactando claramente na qualidade da formação.

Quanto ao EaD, salientamos, por fim, a necessidade de, tanto por pesquisadores da área do Serviço Social quanto pelas entidades da categoria (CFESS/CRESS, ABEPSS e ENESSO), permanecer problematizando amplamente junto à categoria profissional (estudantes, assistentes sociais e docentes, formados ou não via modalidade EaD) as condições formativas da modalidade de ensino, que apontam para uma formação fragilizada, com diversas limitações. Tal problematização deve questionar:

(i) como a modalidade EaD se insere em uma política educacional que tende a aprofundar ainda mais o seu caráter mercantil, principalmente considerando a posição periférica e tardia de um país como o Brasil.

(ii) as condições formativas dessa modalidade, que se relacionam com sua própria natureza, podem ser assim arroladas: ausência de contato com movimentos sociais históricos (como o estudantil e o docente); ausência da transversalidade do tripé ensino, pesquisa e extensão; ausência da vivência acadêmica e do múltiplo e diverso contato com diversos sujeitos inseridos no âmbito acadêmico e profissional (discentes, docentes e supervisores de campo de estágio); as diversas irregularidades encontradas, 
especialmente quando os discentes entram em campo de estágio, no momento da supervisão direta de estágio ${ }^{20}$.

(iii) tais questionamentos precisam articular-se à discussão mais ampliada do direito universal ao ensino superior, em um país com um sistema de ensino superior majoritariamente privado. Ou seja, é primordial demonstrar, no debate junto a discentes, docentes, assistentes sociais e tutores, que não se trata de uma discussão maniqueísta (EaD X presencial) e/ou preconceituosa, mas embasada em estudos e pesquisas sobre a formação profissional e as condições indispensáveis para a formação de profissionais capacitados na tríplice dimensão citada anteriormente, para atender aos usuários com competência e de forma a afirmar/fortalecer o desenvolvimento dos direitos sociais em um país marcadamente desigual como o Brasil.

Nesse sentido, o pano de fundo da discussão é: que perfil de formação profissional faz-se necessário para afirmar os preceitos ético-políticos inscritos no Código de Ética dos assistentes sociais, de $1993^{21}$ ?

Para um perfil coadunante com o Código de Ética, é imprescindível questionar os rumos da política educacional brasileira: mercantilizada e negadora do direito universal à educação pública, gratuita, laica, democrática e de qualidade, em todos os níveis formativos.

O ensino superior e seu caráter predominantemente privado mercantil é uma expressão de uma política educacional voltada para os interesses mercantis não de formar criticamente,

20 Frente à própria natureza do EaD, o momento do estágio em Serviço social carece das condições formativas legais para o seu efetivo exercício. Não à toa, as denúncias aos Conselhos Regionais de Serviço Social (CRESS) quanto a irregularidades nesse momento da formação vêm tornando-se crescentes, especialmente direcionadas para o estágio supervisionado. Cf. documento do CFESS, publicado em 2010, sobre uma série de irregularidades relacionadas à formação na modalidade EaD (CFESS, 2010). Consultar, ainda, a Política Nacional de Estágio (ABEPSS, 2010), construída pela ABEPSS e defendida como parâmetro de qualidade para o processo formativo.

21 Aqui, destaca-se a referência fundamental de um perfil crítico e competente nas três dimensões do exercício profissional (teórico-metodológica, éticopolítica e técnico-operativa) defendido pela Associação Brasileira de Ensino e Pesquisa em Serviço Social há mais de três décadas. Cf. ABEPSS (1996). 


\section{temporalis}

mas de "adestrar" socialmente os sujeitos, conformá-los à lógica desigual reinante.

Assim, é fundamental permanecer tanto na ação política de combate à desigualdade educacional - e o EaD é uma de suas expressões, visto que o Estado não se responsabiliza como deveria, com recursos públicos suficientes, para a garantia da escolarização de todos na idade correta e para o acesso universal ao ensino superior de qualidade e presencial - como no aprofundamento de estudos/pesquisas quanto aos rumos da formação profissional de Serviço Social e suas implicações para o exercício profissional.

\section{REFERÊNCIAS}

AMARAL, N. C. Expansão-avaliação-financiamento: tensões e desafios da vinculação na educação superior brasileira. In: MANCEBO, D.; SILVA JUNIOR, J. R.; OLIVEIRA, J. F.; CATANI, A. M. (Org.). Reformas da educação superior: cenários passados e contradições do presente. São Paulo: Xamã, 2009. v. 1, p. 113-146.

. Financiamento da educação superior: Estado X Mercado. São Paulo: Cortez, 2003.

ASSOCIAÇÃO BRASILEIRA DE ENSINO E PESQUISA EM SERVIÇO SOCIAL (ABEPSS). Diretrizes Gerais para o Curso de Serviço Social. Rio de Janeiro, novembro de 1996. Disponível em: <http:// www.abepss.org.br/briefing/documentos/Lei_de_Diretrizes_ Curriculares_1996.pdf>. Acesso em: 02 jul. 2014.

. Política Nacional de Estágio. 2010. Disponível em: <http:// www.abepss.org.br/briefing/documentos/politica_nacional_estagio.pdf>. Acesso em: 02 jul. 2014.

BRASIL. Lei n. 9.394, de 20 de dezembro de 1996. Estabelece as diretrizes e bases da educação nacional. Brasília, 1996. Disponível em: <http://www.planalto.gov.br/CCIVIL/LEIS/l9394.htm>. Acesso em: 04 jul. 2014.

CONSELHO FEDERAL DE SERVIÇO SOCIAL (CFESS). Associação Brasileira de Ensino e Pesquisa em Serviço Social (ABEPSS). 
Executiva Nacional de Estudantes de Serviço Social (ENESSO). Sobre a incompatibilidade entre graduação a distância e Serviço Social. Brasília: CFESS/CRESS/ABEPSS/ENESSO, 2010. Disponível em: <http://www.cfess.org.br/arquivos/incompatibilidade_ ead_e_ss_cfesscress.pdf>. Acesso em: 02 jul. 2014.

GERMANO, J. W. Estado militar e educação no Brasil (1964-1985). São Paulo: Cortez, 2005.

INSTITUTO NACIONAL DE PESQUISAS EDUCACIONAIS ANÍSIO TEIXEIRA. Ministério da Educação (INEP/MEC). Sinopse Estatística da Educação Superior 2012. Brasília: INEP/MEC, 2012. Disponível em: <http://portal.inep.gov.br/superior-censosuperior-sinopse>. Acesso em: 15 jul. 2014.

. Sinopse Estatística da Educação Superior 2011. Brasília: INEP/MEC, 2011. Disponível em: <http://portal.inep.gov.br/superior-censosuperior-sinopse>. Acesso em: 15 jul. 2014.

. Sinopse Estatística da Educação Superior 2010. Brasília: INEP/MEC, 2010. Disponível em: <http://portal.inep.gov.br/superior-censosuperior-sinopse>. Acesso em: 15 jul. 2014.

. Sinopse Estatística da Educação Superior 2009. Brasília: INEP/MEC, 2009. Disponível em: <http://portal.inep.gov.br/superior-censosuperior-sinopse>. Acesso em: 15 jul. 2014.

. Sinopse Estatística da Educação Superior 2008. Brasília: INEP/MEC, 2008. Disponível em: <http://portal.inep.gov.br/superior-censosuperior-sinopse>. Acesso em: 15 jul. 2014.

. Sinopse Estatística da Educação Superior 2007. Brasília: INEP/MEC, 2007. Disponível em: <http://portal.inep.gov.br/superior-censosuperior-sinopse>. Acesso em: 15 jul. 2014.

. Sinopse Estatística da Educação Superior 2006. Brasília: INEP/MEC, 2006. Disponível em: <http://portal.inep.gov.br/superior-censosuperior-sinopse>. Acesso em: 15 jul. 2014. 


\section{temporalis}

. Censo da Educação Superior 2009 - Resumo Técnico. Brasília: INEP/MEC, 2010. Disponível em: <http://download.inep. gov.br/download/superior/censo/2009/resumo_tecnic02009. pdf >. Acesso em: 12 jul. 2013.

- Censo da Educação Superior 2011 - Resumo Técnico. Brasília: INEP/MEC, 2013. Disponível em: <http://download.inep. gov.br/educacao_superior/censo_superior/resumo_tecnico/resumo_tecnico_censo_educacao_superior_2011.pdf >. A Acesso em: 12 jul. 2013.

LIMA, K. R. S. Contrarreforma da educação superior: de FHC a Lula. São Paulo: Xamã, 2007.

NEVES, L. M. W. (Org.). O empresariamento da educação: novos contornos do ensino superior no Brasil dos anos 1990. São Paulo: Xamã, 2002.

SGUISSARDI, V. Modelo de expansão da educação superior no Brasil: predomínio privado/mercantil e desafios para a regulação e a formação universitária. Revista Educ. Soc., Campinas, v. 29, n. 105, p. 991-1022, set./dez. 2008. Disponível em: <http://www.scielo.br/pdf/es/v29n105/v29n105a04.pdf>. Acesso em: 10 jul. 2013.

SGUISSARDI, V.; SILVA JUNIOR, J. R. Trabalho intensificado nas federais: pós-graduação e produtivismo acadêmico. São Paulo: Xamã, 2009. 